\title{
The Comparative Study of Privacy in Designing Qajar Dynasty Isfahan`s Houses and Malaysia`s Traditional Houses
}

\author{
Zahra Kazemi Zahrani* and Seyedeh Marziah Tabaeian \\ Department of Architecture, Isfahan (Khorasgan) Branch, Islamic Azad University, Isfahan, Iran. \\ *zahrakazemizahrani@yahoo.com
}

\begin{abstract}
Privacy is taken from cultural and religious values and belief which are among the rules of the traditional residential architecture which have been shown in different ways in traditional architecture in different ways. Lots of valuable characteristics of the traditional Iranian houses prove the fact that Iranian people kept privacy; nowadays with the penetration of western architectural culture and after Qajar dynasty, a reflection of that style is rarely seen in contemporary residential architecture. This survey is to analyze privacy layering in Iranian architectural houses and as a religious value by the use of the mentioned method (observation, interview, and studying the maps) in the traditional sample of Malaysia as the comparative sample and then compared with the other Malaysian samples. By taking the nature of the objective of the research into considerations, the research method is comparative case study based on qualitative approach. Results of this survey have shown that privacy in different layers were designed for keeping people`s independence, and providing the mental and psychological peace of the family member which is completely consistent with Islamic sources; there are some similarities and difference between the Malaysian sample and two samples of the early and late of Qajar period. The conclusion of this study shows the existence of extrovert privacy pattern in Malaysian houses and also existence of introvert privacy pattern in Qajar houses and different spatial categorizations; the privacy keeping principle and approaches in contemporary architecture is applicable.
\end{abstract}

Keywords: Privacy, Hierarchy, Being introvert, Isfahan`s Qajar Houses, Traditional Malaysian house.

\section{INTRODUCTION}

The effect of culture's subcategories like ideology, believes, traditions, life styles, and people's mental, psychological, social, and individual need in forming biological spaces, after providing a shelter, is important. The role of each building like a house as part of an architectural culture is to create reality the thoughts by the use of its means; it is in a way that this means would be the criteria for validating the culture. Therefore privacy is a considerable issue here, it means keeping the personal privacy by considering its relational meaning in each society and culture (Rapoport, 1969). Based on the findings of such researchers like Rapoport, culture as an effective factor in social stability plays a crucial role in forming process. The role of religion in forming such cultures is effective. Diverse patterns of buildings in an area with diverse religion prove this issue (Altman, 1993). Almost all of the researches in social behavior analyze privacy, culture, religion, and environment altogether (Altman \& Low, 1984). Based on Altman`s definition of privacy, this concept is as an option that a person determines for managing his/her availability (Altman,
Irwin, \& Chemers, 1984). Newell defines privacy as the temporary separation of human and public places based ownership rules. He believes that changing human's condition in private and public places is because of its innate distinction. Margulis(2013) also analyzed privacy and maintain that this concept as sectional and sometimes holistic phenomenon controls the individual and the other people's relationship. Therefore, sociologists called privacy as a border between individual, others, and environment that people empowered limit or spread the borders (Faahi, 1995). Meanwhile Mortada (2003) maintain privacy as an religious concept for gender separation and also the separation between private life and public interaction. Designing the introvert traditional houses was with out any window and with enclosed yard. One of the used principles in designing Iranian houses is availability hierarchy which causes the categorization of the space into different parts and the creation of a spatial privacy (Naghizadeh, 2000).

Definition of privacy: the word "privacy" is taken from the Arabic root of "Haram"; semantically, it is translated as being familiar, confident, and secrecy. 
Privacy in architectural environment means "space creation" in a way that it would be private from both framework and meaning aspects. Having privacy in the spatial framework is based on the principles which cause the formation of the spatial security, from the meaning aspect, it refers to the characteristics that which bring value for the architectural spaces in a way that it causes the person to be in peace (MahdaviNezhad, 2011). Based on Rapoport's view point, privacy is an ability in controlling social relations and the power to select special desirable amount of this relation. Jon Lang (2012) believes that almost all of the definitions of privacy have the same and common characteristic which refers to the ability of the person or a group of people in controlling the social, visual, auditory, and sensational relations with others. Privacy, as one of the fundamental principles of Islam, Has been adhered in the design of houses in Iran and Malaysia. Different climatic conditions of these two realms affect their privacy preservation strategies. The aim of this study is to investigate the differences and similarities of these strategies.

\section{LITERATURE REVIEW}

\section{a. Moslem's Viewpoint Regarding Keeping Privacy At Home}

According to Islam`s perspective, house is a safe and private shelter which is the best place for having peace and enjoying life. There are lots of such examples in Holy Qur`an, like:

"Do not enter the house in which nobody is there, unless you have got permission, but if they asked you to go back ...." (Noor Sura, 27)
The concept of keeping and protecting privacy in Islam differentiates the private life from outside interactions which separates women and unfamiliar men with the aim of providing family security. Mortada (2003) believes that house is the key factor for reaching women's privacy hierarchy from visual and auditory aspects. Reaching the house privacy provides the condition for them to keep secure and safe women against foreigners and unknown men. Providing visual privacy is possible in two positions: at home and also in relation with the Other houses and secondly inside the houses (Asiah, 2008).

\section{b. Islam Religion and Residential Architecture In Iran}

After the time that Iranian people get Moslem, the approach and the level of women an $d$ men's relationships have changed. Based on Islamic believes, Moslems houses must be a symbol of peace and tranquility. Accordingly, Iranian traditional houses are generally based on protecting privacy and keeping cultural-religious value of hospitability. It is in a way that our prophet recommended his followers not to enter a place suddenly or secretly.

"The person who is entering somewhere must declare his/her entrance" (HorAameli, 1985)

In fact privacy preserves and protects people when they are a lone to provide the condition for them to concentrate on their loneliness and have a balance between inside and outside. Entryway, hallway, and the stairs reaching the front yard are the elements which provide the supportive privacy part of the houses. Iranian traditional houses have diverse entrances to manage the entrance of different people (Figure1).

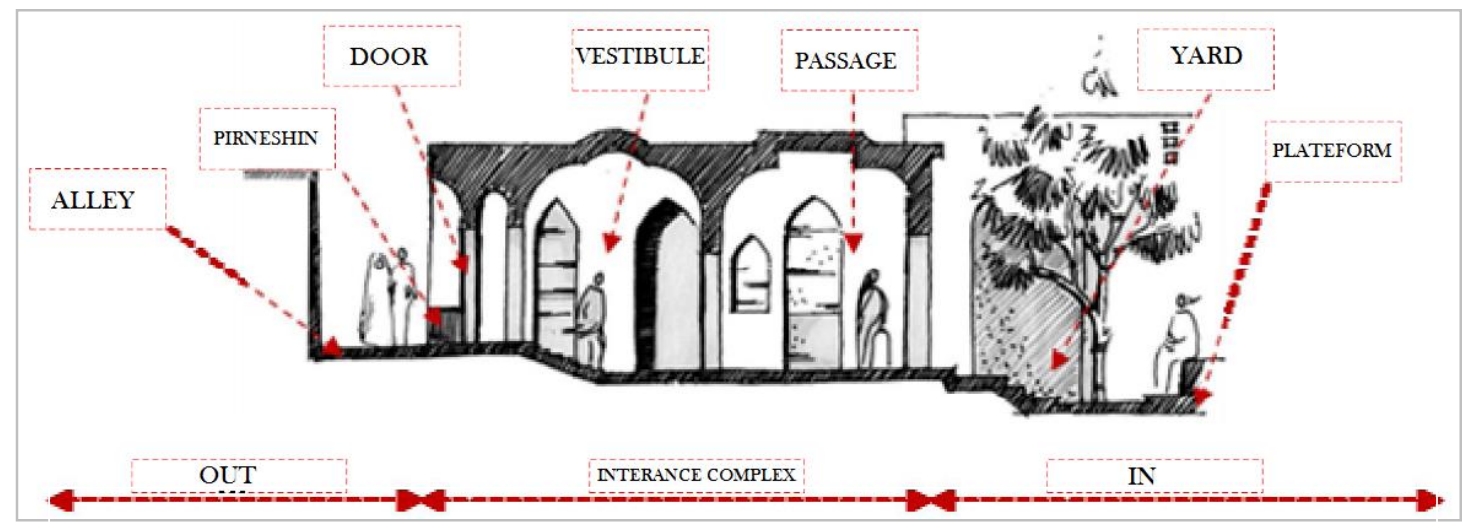

Figure 1: The hierarchy of the entrance of Iranian traditional houses (Nayeri Fallah, 2013) 


\section{c. Iranian Traditional Houses And The Concept Of Privacy}

Totally, habitation as shelter is necessary for protecting and preserving the habitants against natural events, also it is a place to reach the physic and psyche's health, rest, and spirit's tranquility (Rasdi, 2011). The pattern of Iranian families' life is based on intimacy, cooperation, and social relations (Haeri, 2010). Beside the previous categorizations regarding the space of Iranian traditional houses like seasonal (Memarian, 1994), and availability categorizations (Pirnia, 2011), it is obvious that how religious designs provide the condition for holding the special religious ceremonies without facing any problem. This layering exists in almost all of the Iranian traditional houses by taking the structures` facilities, climate, domestic conditions with form diversities into consideration (Zamarashidi, 2007).

\section{d. Privacy Creation Factors In Iranian Houses}

Active architectural experts in the field of Islamic principles focus on three determining privacy factors. The related examples of this regard are as the doors, windows, openers, the wall's height, and the curtains (Hakim, 2011). The entrance of the building is one of the important factors. Beside entrance, window consider as the most important factors. Hakim (2011), Mortada (2003), and Asieh (2008) in this regard believe that the windows height in the grand and first floor must be higher than the height that the eye sees to keep the visual privacy of the inside space of these floors (Figure 2).

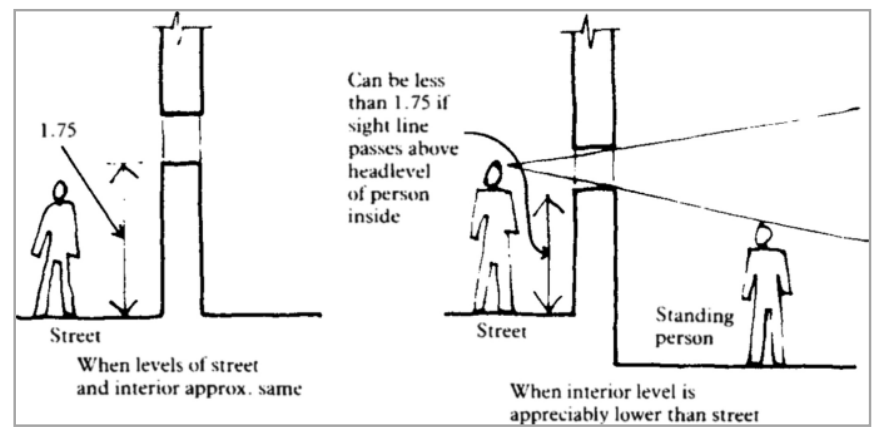

Figure 2: The windows height in the Muslims' houses to keep privacy (Altman, 2015)

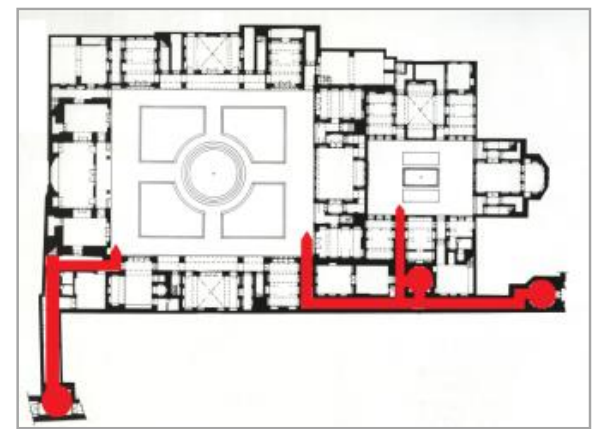

Figure 3: Entryway and the path of penetralia (inside) and the drawing room

Entryway: entryway as the pre-entrance space prevent the direct sight of the inside part of the private space which proves the existence of privacy rules in the Iranian houses. In fact the entryway is a hesitation for facing two different spaces (Figure 3). In order to provide more security for the residents, such complex plan was used deliberately (Soltanzadeh, 1993).

Penetralia (inside) and the guestroom (living room) is the place that family members live there and outsiders are not allowed to enter there. Drawing room is just specialized to the guests and outsiders who entertained separately (Soltanzaded, 2006). In the architecture of Iranian traditional houses, there was a special room assigned to the guests which is called drawing room or Panjdari (Pirnia, 2003). In this regard, the most outstanding effect of Islam in the construction of a traditional house is being introvert. Burckhardt (1990) believes that yard is a feature of Muslims` houses. As he said: "The sunlight of the Muslim`s houses is gotten from their yard, not the streets."Penetralia (inside) are considered as the most private traditional yards (Figure 4). 


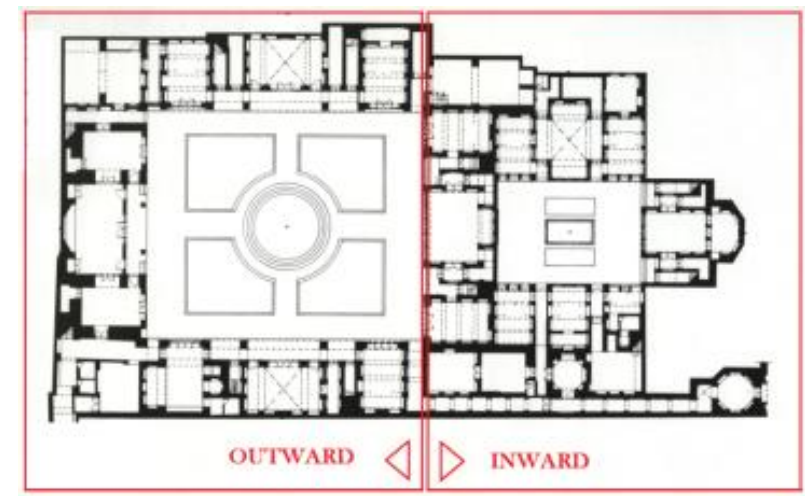

Figure 4: Locating Penetralia (inside) and drawing room in Qajar`s architecture Isfahan`s organization of cultural heritage archive, 2016

\section{PURPOSE OF THE STUDY}

The purpose of the present research is fourfold layered analysis of privacy as a value in the architectural spaces of Iran`s traditional houses. Therefore, Qajar houses of Isfahan were selected to be analyzed. The suitable position to see and analyze these housesin a field study was the reason of their selection, because they were belonged to the normal class of society and lots of historical documents were existed, in order to be more resembled to the Malaysian sample and would be more comparable. The subcategories of this fourfold categorization as the base of the spatial system of the house is useful for providing privacy principles which are as public, friend, relatives, and the neighbors space/part and totally the outsiders (Rasdi, 2011). The private space/part is the area of family member in a way that there is not any contact between family members and the outsiders or foreigners. Two other areas include semi-public and semi-private space/part which include the middle spaces of the two mainspace/part.

\section{RESEARCH METHOD}

By taking such factors like culture, religion, traditions, and climate on people's life style and customs into consideration, this research is trying to analyze privacy factor in two different types of climate. The two studied countries are Muslim in terms of religion and warm in temperature, but they are quite opposite in terms of humidity, and this has consequently led to different types of design principles while respecting privacy. In line with the mentioned factors, Malaysian date presented by Razali which is a kind of traditional and religious sample was selected from among different kinds of Malaysian traditional residential.
This type is one of the most important parts of Malaysian residential in which Islamic privacy factor counted on it (Rezaaly, 2013). In the first step two samples of Isfahan`s Qajar house were selected which are comparable in terms of dimensions and antiquity and culture of the two countries. Yadollahi house was the sample of the earlier period of Qajar dynasty and doctor Aalam`s house was the sample of the research during the late period of Qajar dynasty and nearly a wealthy class of the society which are located in Chaharbagh Pain area. The studied samples in both countries are similar in several aspects:

1) Both are Muslim houses.

2) Principles of privacy are adhered in their Architectural design.

3) Bothare samples of traditional (nonmodern) architecture of their own country.

4) The residents live together as a set. (Including father, mother, children, and grandparents).

5) The samples are located in a warm climate.

At the beginning the history of buildings was studied and the related maps have been attained. This study has been done by interviewing expertise (Ghasemi , Jabalameli and Valibake ) in these 3 fields, in order to identify different parts of the building and the usage of each of them and useful recognition of Women and men in each space. As the Iranian samples are uninhabited and the areas of privacy and seclusion could not be found out through observation and interviewing with users and residents, In order to identify the different parts of the building, their use, the beneficiaries (male or female) of any space, type of gender segregation, and the way of using each area, interviews with experts in this field was conducted. The interview questions include: 1. Determining the fields related to the women, 2 . Determining the fields 
related to the women 3 . Determining the common and the separated fields of men and women, 4. Determining the activities that have been done in each place (social and private life), and 5. Determining the reasons of separation of four-fold fields. Mark the plan and determine the limit of privacy in plan and view should be done after getting familiar with the Fourfold layers of privacy.

\section{RESEARCH FINDINGS}

The present research is to analyze the fourfold categorization of public, semipublic, private and semiprivate parts mentioned by architectural expertise. Also an accurate analysis of the previous family life style and analyzing Iran`s traditional houses have been achieved. The mentioned layering and architectural approaches in order to have a gender separation and being careful in the safety of vulnerable members of family like women and children have shown in the form of analytic diagrams, tables and maps. It is indicated in the figures related to the diversity of layers and locating each one. The extension of each layer is determined based on the life requirement and its application. The semipublic layer include the total level of yard and hallways and it is the most extended privacy layer, because the important events of life and main interactions happen in the yard and require such more widespread space. The semi-privacy layer applied in more unique and limited interactions which

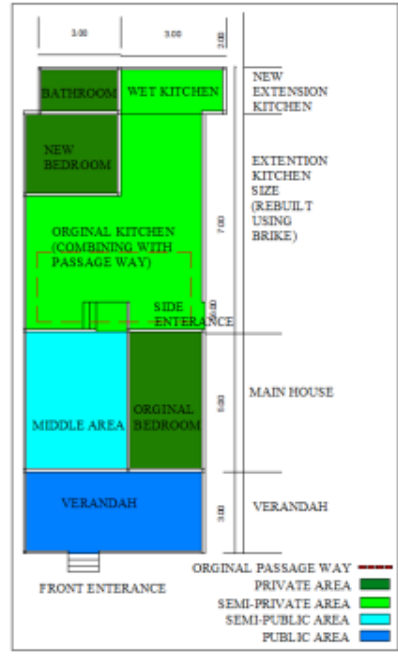

Figure 5: Privacy layers in a Malaysian house (Razali, 2013)

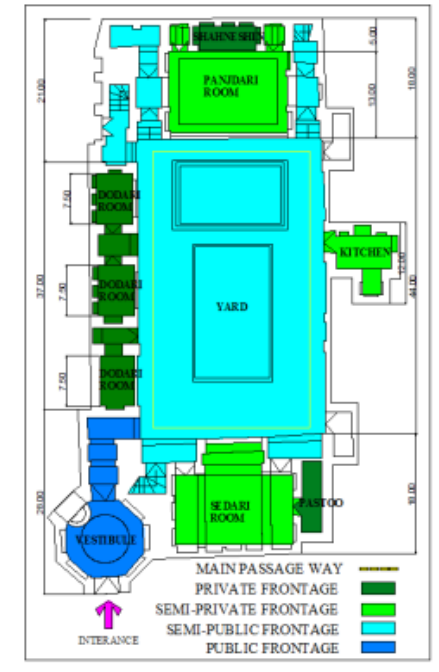

Figure 6: Privacy layers in a house (Yadollahi House) in the early period of Qajar dynasty (Razali, 2013) is less widespread than semi-public layer. The private layer which is a place for sleeping and taking rest of the family members was assigned lesser space and finally the application of public-layer which is only a place to enter, getting permission and reside there for a short time was assigned a more widespread space to itself. The private layering in the case studies including Malaysian residential, Rahim Yadollahi and Aalam in Isfahan In Figure 5,6, and 7 is observable. The privacy layering and architectural approaches of Qajar house is shown in Table 1.

The privacy layering in Malaysian residential IS shown in figure 5. (Rezali, 2013) The privacy layering in the house of the early period of Qajar dynasty (Yadollahi house) is shown in figure 6 (authors, 2015) The privacy layering in Isfahan's house in the late period of Qajar (Aalam) is shown in Figure 7 (authors, 2015) The Malaysian residential, Yadollahi house and Aalam house are shown in the Figure 6, 7, and 8 respectively. (author, 2015). The fourfold parts of Yadollahi and Aalam's houses were located from public to private respectively. It indicates the spatial hierarchy in order to get ready to enter and take permission to enter into the other parts of the house. Figure 5, 6, 7, 8, and 9. 

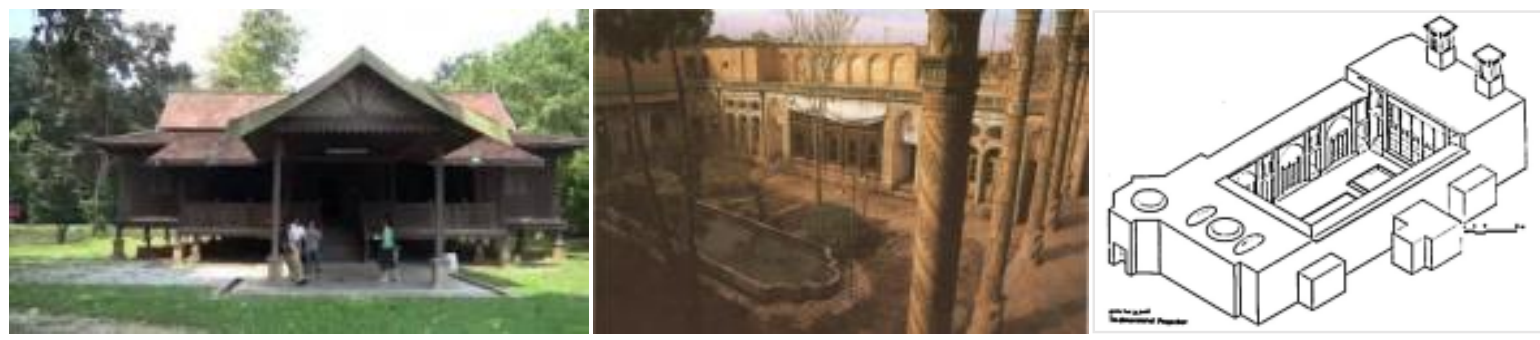

Figure 8: Malaysian House Dr. Aalam, and Dr. Yadollahi House respectively (left to right), 2015)

\section{Layers of Privacy}

Public layers, these are the spaces ended to the entrance set and the related parts. Semi-public layers include passage ways and public available places which were located along the public layers. Semi-privacy layers include spaces in which women have interaction with their friends, neighbors and relatives. This part is available just from the yard`s door like kitchen and sitting room, Se dari or alcoveand Pang dari (drawing house), living room, and hall. Private layers are including the daily life spaces of family members like bedroom, private spaces and the living room (Do dari). Providing the privacy would be possible by determining the position of door, windows, walls, adjacency, neighborhood, roof light places and also covering some of windows by curtain. Providing the privacy of availability by adjacency of internal spaces based on privacy hierarchy. Providing the auditory privacy would be possible by having a spatial place, using suitable material, performing consistent with the features of sound transference; blinding the curtains implicate that children`s noise in the yard is not problematic.

Providing the smell privacy is possible by a suitable creation of ventilation, being careful about the location of the windows and determining a good location for kitchen would be a good solution. Providing privacy in the realm of family`s social interactions by considering men and women`s needs separately like creating an alcove for separating the limit of guest of honor and host in the ceremonies.

Table 1: Procedures and concepts for keeping privacy in Qajar houses in Isfahan (Authors, 2015)

\begin{tabular}{|c|c|}
\hline Privacy layers & $\begin{array}{l}\text { - The public layers: it includes the spaces ended the entrances and its } \\
\text { belongings. } \\
\text { - Semi-public layers: the passage ways and the places which have public } \\
\text { accessibility a long with the public layer. } \\
\text { - Semi-private layers: it includes (1) the places which women have } \\
\text { communication and interaction with their relatives and their neighbors and } \\
\text { have gather together in the external yard; like kitchen. (2) The place which } \\
\text { family members gather there: Panjdari (drawing room) and Se dari } \\
\text { (alcove). The place was the guests entertained: guest room. } \\
\text { - Private layer: the supportive spaces of the family`s daily life which include } \\
\text { bedroom and the private places (Do dari)S }\end{array}$ \\
\hline $\begin{array}{l}\text { Architectura } \\
\text { measurements }\end{array}$ & $\begin{array}{l}\text { - Providing the visual privacy because of the main entrance, windows, walls, } \\
\text { and the neighborhoods, having the roof light and covering some of the } \\
\text { windows } \\
\text { - Providing the privacy accessibility, for bring near the interior spaces based } \\
\text { on privacy hierarchy } \\
\text { - Providing the auditory privacy as a result of correct spatial location, the } \\
\text { proper performance in consistent with the sound transference traits and } \\
\text { also the Se dari (alcove) curtain. } \\
\text { - Providing the auditory privacy: by providing the smelling privacy, } \\
\text { installing proper ventilation and being accurate while installing the } \\
\text { windows and also selecting a suitable space for kitchen } \\
\text { providing auditory privacy: by providing privacy in the era of the family`s } \\
\text { social interactions and also by taking women and men`s needs separately } \\
\text { like having alcove for the separation of the guest and host place in the } \\
\text { ceremonies into consideration }\end{array}$ \\
\hline
\end{tabular}


As it is considerable in Dr. Aalam`s House, there is a new factor named "porch" has been added to the Iranian houses which takes effect the privacy layering and causes the creation of a new position in a way that the yard provides more privacy for the rooms, but in the porch more sight and lesser privacy is considerable. (Figure 6, 7, 8, and 9). The concept and principles of keeping privacy in the Qajar Houses in Isfahan (2015)

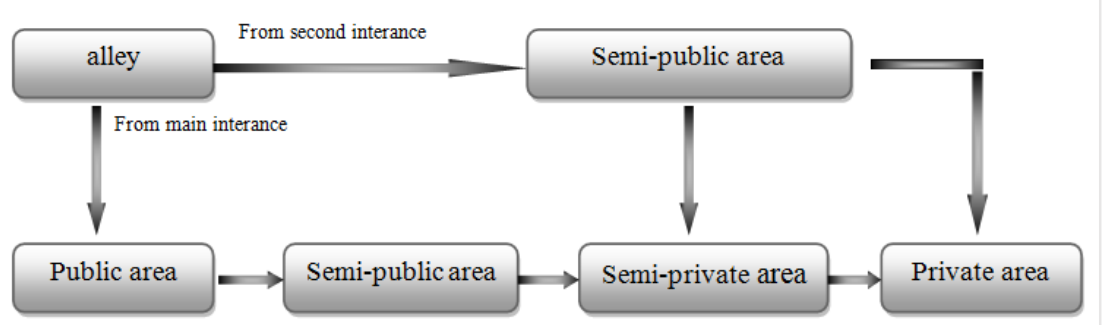

Figure 9: The hierarchy of accessibility of the Qajar houses in Isfahan (Authors, 2015)

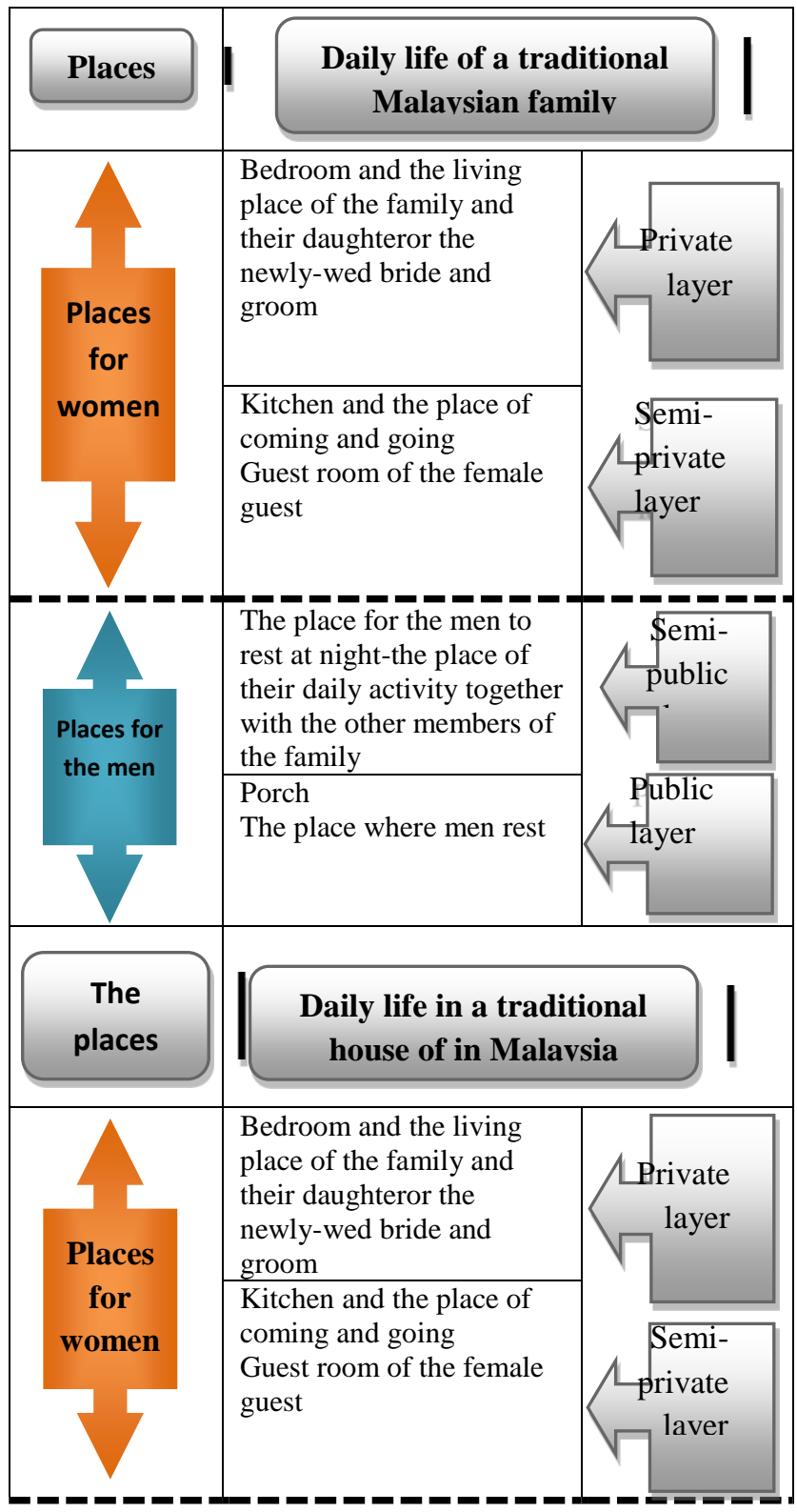




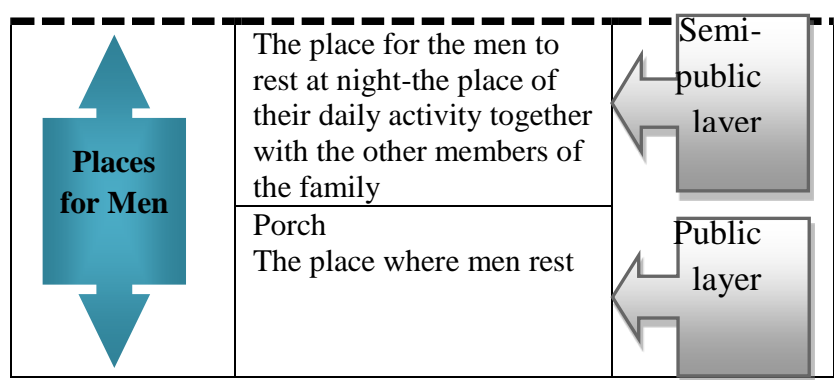

Figure 10: The fourfold usage of privacy in Qajar houses and the Malaysian

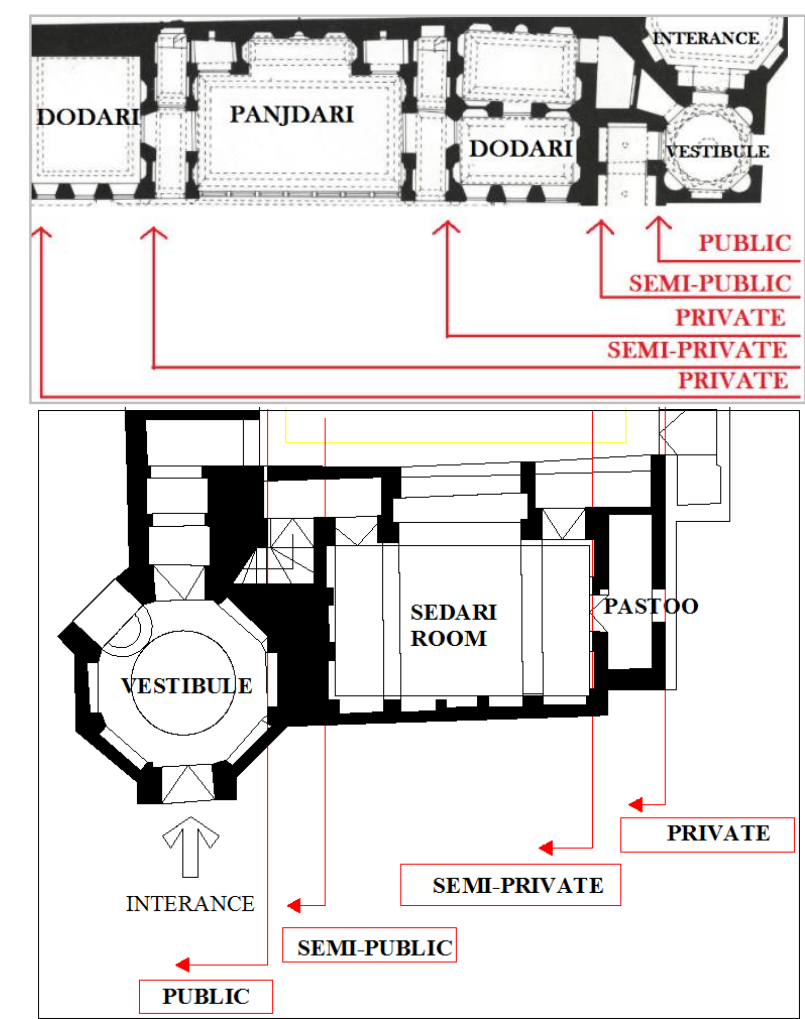

Figure 11: The order of the privacy layers arYadollahi and Dr. Aalam`s House, (Authors, 2015)

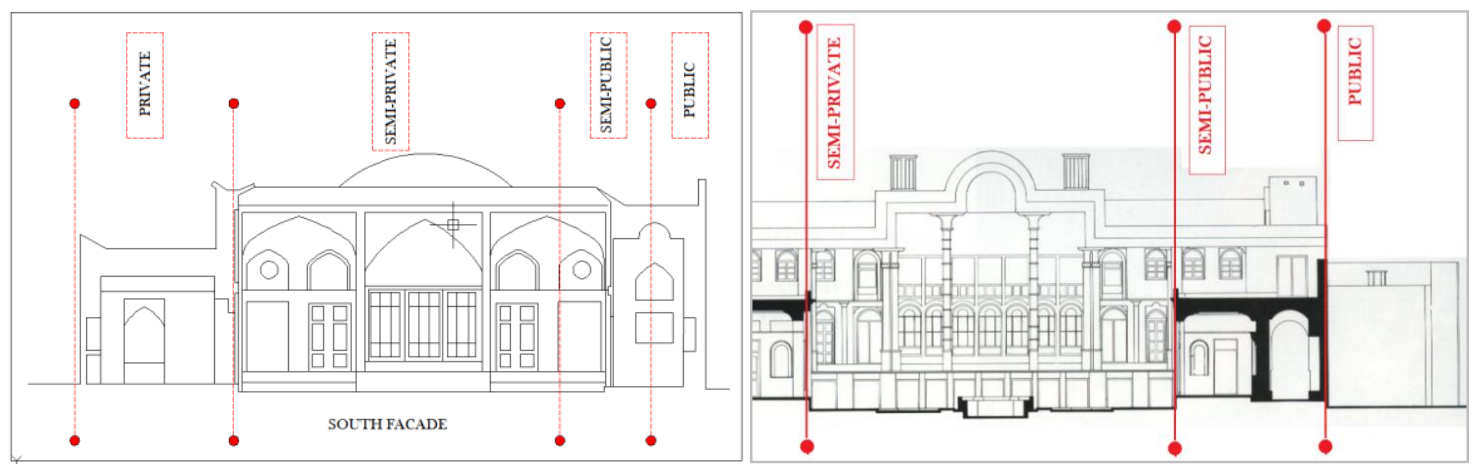

Figure 12: The order of the privacy layers arYadollahi and Dr. Aalam`s House, (Authors, 2015) 

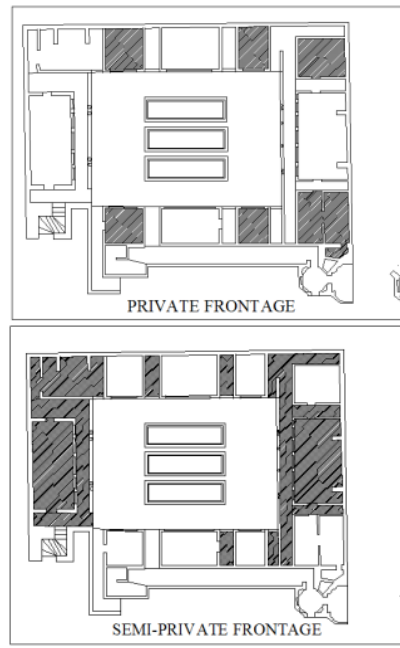

Figure 13: Fourfold layers of privacy from left to right: Malaysian,

Yadollahi, Dr. Aalam Houses, the author (2015)
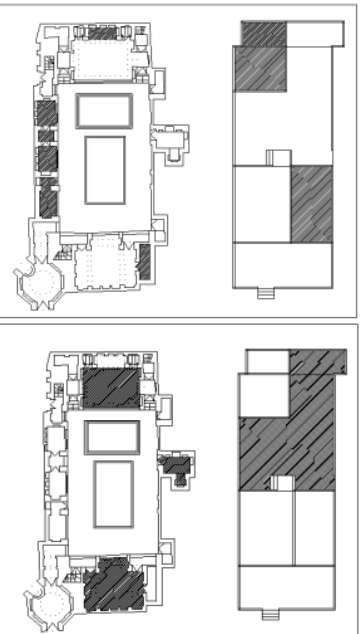

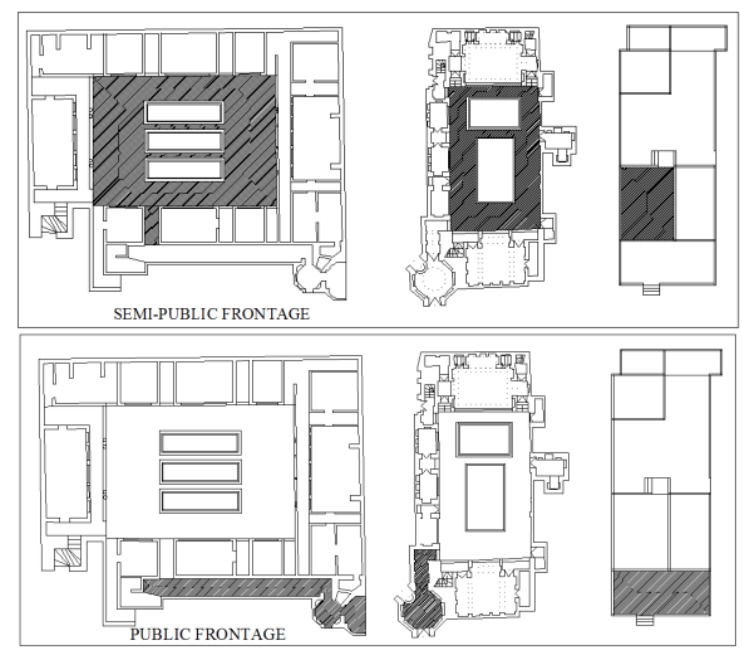

Table 2: Comparative analysis of privacy layers in Qajar Houses in Isfahan and Malaysian House (Authors, 2015)

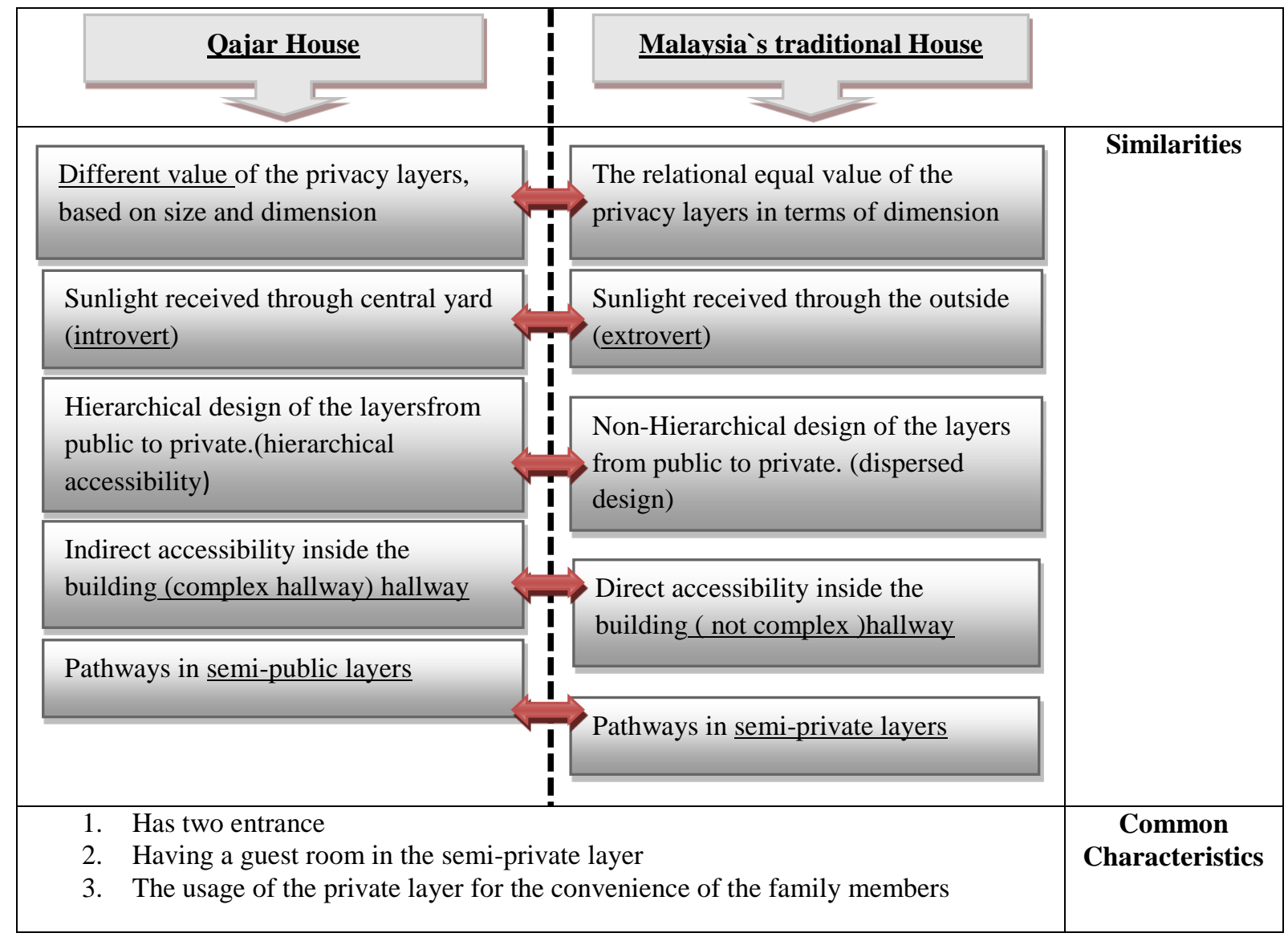


Figure 10 shows the privacy comparison of Qajar and Malaysian House. Also in figure 11, 12, and 13 the analysis of locating the privacy layers was shown. At last in Table 2.the similarity and the differences of privacy in two different climates is been explained.

Findings resulted from the analysis of collected data have shown that the effective principles for the creation of Iran's traditional houses include: Islamic believes, cultural criteria, life style of the families, social relationship modeling and the behavioral criteria of Iranian people. The religious principles play a crucial role in increasing the quality of family life and space creation in houses by emphasizing the concept of privacy. Paying attention to the principles of men and women 's separation and individual's visual privacy beside the spatial availability of privacy are the fixed principles of Iran`s traditional houses.

\section{CONCLUSION}

The case studies of the houses were corresponded in terms of spatial division and layering, but factors like climate, culture, the usage of privacy approaches, designing the layers, and the way of availabilities and accessibilities and dimensions were effective; In terms of climate: in a way that, Malaysian samples and Qajar's samples in Isfahan have shown extrovert and introvert privacy respectively. But in terms of ensuring privacy, both samples are similar in the following cases:

1) Observing the hierarchy of access from public to private.

2) Positioning private areas in the periphery.

3) Positioning semi-private and semi-public areas in the center.

4) Having the main entrance in the public sector.

5) Having a secondary entrance from the semiprivate sector.

Totally the privacy and architectural approaches were more observable in Qajar samples. But privacy in Malaysian samples is not as important as the previous one. Different ways of privacy creation in the case studies are as:

1) Lack of having direct sight inside the house by making a good location in entrance.

2) Having a breathing (dead) space after entrance in order to make ready to enter.
3) Locating the restroom place in a way that nobody can enter the private space.

4) Having the correct separation of private spaces from the public spaces.

5) Having the proper connection between the private and public spaces with middlespaces in order to provide privacy and convenience.

6) Having the correct location of semi-public and semi-private spaces.

7) Not having enough space from the adjacent, neighborhood spaces and other rooms into the public spaces.

8) Designing to create a visual privacy by using the mentioned approaches.

\section{REFERENCES}

Altman, I, \& Low, S. (1992). Human behavior and environments: advances in theory and research York: Plenum Press.

Altman, I. (1993). The Environment and Social Behavior: Privacy, Personal Space, Territory, and Crowding (A. Namazian, Trans.). Tehran: Shahid Beheshti University Press.

Asiah, A. R. (2008). Housing from the Islamic Perspective (1st ed.). Kuala lampur: IIUM Press, International Islamic University Malaysia

Burckhardt, T. (1990). Sacred Art in East and West: Its Principles and Methods (J. Satari, Trans.). Tehran: Soroush Publication.

Fahey, T. (1995). Privacy and Family: onceptual and Empirical Reflections. Sociology Journal of the British Sociology Association.

Haeri, M. R. (2009). The Role of Space in Iranian Architecture. Teheran: Cultural Research Bureau.

Holy Quran. (2007). (H. Elahi Qomsheei, Trans.). Qom: M, Alhadi publication.

Hor Ameli, M. (1985). Vasael al Shea:jihad al-nafs (A. Sehat, Trans.). Tehran: Nas.

Jabal Ameli, A. (1995). isfahan's Houses in the Contemporary Era. Paper presented at the The First Congress on the History of Iranian Architecture, Kerman-Arg-e Bam.

Lang, J. (2011). Creating ArchitecturalTheory: The Role of the Behavioral Sciences in Environmental Design (A. Eini Far, Trans.). Tehran: Tehran University Press.

Mahdavinejad, M., \& Mashayekhi , M. (2011). Principles of the Socio-Cultural Mosque Design Based on Socio-Cultural Approach. Armanshahr Journal. 
Memarian, G. H. (1994). Familiar with Iranian residential architecture :introspective typology. Tehran: Soroush Danesh.

Margulis, S. T. (2003). Privacy as a social Issue and Behavioral Concept. Journal of Social Issues,

Naghi Zadeh, M. (2000). The Philosophy of Hierarchy in Architecture and Urbanism. Paper presented at the 2ndCongresson the History of Iranian Architecture, Kerman- Arg-e Bam.

Mohd Razali, N. and Talib, A. (2013) The Concept of Privacy and the Malay Dwelling Interior Space Planning.

Mohamad Rasdi, M. tajuddin bin. (2011). Architecture and Nation Building, Community, Religion, Politics and Education. Johor: UTM press.

Mortada, H. (2003). Traditional Islamic Principles of Built Environment. Routledge.

Hakim, B. S. (1989). Arabic Islamic Cities: Building and Planing principles (p. 256. Routledge.

Newell, P. B. (1995).Perspectives on Privacy. Journal of Environmental Psychology.

Othman, Z. Aird, R. and Buys, L. (2015), Privacy, modesty, hospitality, and the design of
Muslim homes: A literature review, Frontiers of Architectural Research.

Nayyeri Fallah, S., Khalili, A., Ismail, A. S., \& Rasdi, M. T. (2013).An Evaluation of Entrance Spaces in Modern Iranian Housing from a Cultural Perspective. Jokull Journal.

Pirnia, M. K. (2004). Stylistics of Iranian architecture. Tehran: Memar Publication.

Rapoport, A. (1969). House Form and Culture (p. 162). Englewood Cliffs, USA: Prentice Hall.

Soltanzadeh, H. (1993). Entrance Spaces in Iranian Traditional Architecture (1st ed.). Tehran: The Cultural Heritage Organization.

Soltanzadeh, H. (2004). Entrance Spaces in Iranian Traditional Architecture (2nd ed.). Tehran: Cultural Research Bureau.

Zmarshidi, H. (2006). Iranian Architecture:Implementing Buildings with Traditional Building Materials. Tehran: Zomorod Publication. 